\title{
Information-Sharing-Based Linkage Mechanism: Pre-Warning and Relief of West China Sudden-Onset Disasters
}

\author{
Jianghua Luo ${ }^{1}$, An'e Wang $^{1} \&$ Dong Yang ${ }^{1}$ \\ ${ }^{1}$ Key Research Institute of Humanities and Social Sciences at University, Center for Studies of Education and \\ Psychology of Ethnic Minorities in Southwest China, Southwest University, Chongqing, China \\ Correspondence: Jianghua Luo, Center for Studies of Education and Psychology of Ethnic Minorities in \\ Southwest China, Southwest University, 2 TianSheng Road, Chongqing 400715, China. E-mail: \\ swusun@swu.edu.cn
}

Received: April 19, $2013 \quad$ Accepted: May 11, $2013 \quad$ Online Published: June 28, 2013
doi:10.5539/ass.v9n9p163

The study is supported by the found of The Key Project of Key Research Institute of Humanities and Social Science of Ministry of Education "Comparative Study on Educations of Races across Borders in Southwest China" (Grant No.: 11JJD880028)

\begin{abstract}
Information absence and communication discontinuity affect the efficiency of pre-warning and relief in those West China sudden-onset disasters and social mass incidents. It's urgent to figure out how to monitor the fragile nature ecology by using the platform of GIS and database and how to enhance the effective communication between government and the people by the rational utilization of internet work. To construct an information-sharing based linkage mechanism, the government should cooperate with social forces, grassroots communities and schools, and respect the value of traditional information approaches in ethnic culture. The intensive use of modern information technology can help dig various groups' intelligence to avoid information absence. By integrating academic research sources related to sudden-onset disasters and forming a knowledge network of disasters prevention and control, we can make the decisions of pre-warning and relief more open and transparent.
\end{abstract}

Keywords: information sharing, sudden-onset disasters, pre-warning and relief

\section{Introduction}

The built of information -sharing-based linkage mechanism is really significant in coping with sudden-onset disasters in west china. As we know, West China is a geological and climatic transition zone where natural calamities frequently happen. In recent years, blindfold and excessive development has aggravated the disasters in those regions. The monitoring and relief of natural calamities requires the dynamic gathering and continuous feedback of information, in which information-gathering and information-delivering are crucial.

However, the information feedback, the database and the application of GIS for west China nature disasters are still in a fledging period. Traditional information methods of ethnic minority villages are usually ignored during most of the pre-warning and relief process. Overly dependent on modern communication medias can lead to the deficiency and inaccuracy of information in sudden-onset disaster management.

In the transition zones between the first and the second steps and between the second and the third steps in the geographical structure, the areas of West China are vulnerable to various geological disasters, and also the concentrated communities for ethnic minorities. In recent years, China's development strategy is mainly focus on the west, where is in its transformation period and face with problems of social-reform and social-instability, along with the increasing complicated situation of geopolitical order, those factors highlight the importance of the stability of west China in the process of social harmonious development. In the modernization process of west China, instability factors are still existed due to economic development gap, culture difference and various religious believes. Those factors may breed some sudden major disasters that threaten the social-stability and social security in west China. (Shi, 2006). How to launch information communication and interaction between publics and governments and to handle sudden-onset efficiently by the properly using of internet, is still a 
problem for the government.

\section{Research Methodology}

This paper start with the analysis of characteristics of sudden-onset disasters and social mass incidents in west China, then launch a discuss centre on the practice of information technology-based disaster precaution and reduction. The authors also referenced some relevant research findings like nature disasters monitoring and emergency management, etc, and adopted methods such as participant observation, web survey and interviewing .

All those statistical data is based on The National Summary and Evaluation Report on Disaster Response Work and An Overview of the National Emergency Management Work, etc. In addition, materials published by provinces and regions like The General Situation and Innovation Analysis of Emergency Management are collected and integrated as the evidences of the paper, along with those relevant research data.

The introduction and analysis of typical cases comes from fieldwork findings and some news reports are added as supplement. The collected materials and data are mainly about: (1) The emergency communication strategies used after Wenchuan earthquake and Yushu earthquake. (2) The importance of "information disclosure and communication" in handling Menglian "7.19" incident. (3) The using of "micro-blogYunnan" in "network politics" by Yunnan governments at all levels.

For the database of west China nature disasters, the authors made a survey of the construction dates, maintenance organizations, network searching, addressable websites, etc. also, the authors combed through some recent academic researches about the using of GIS in monitoring nature disasters occurred in west China.

Some small-scope interviews are made during the research processes, in which grassroot government officials, villages of ethnic minorities, teachers and students in village schools are included. Interviews are mainly reference to topics below: (1) whether the minorities' traditional information tolls still get its value today. (2) How can we integrate the amateur communication tools with specialized communication net of government? (3) How to upgrade people's knowledge attainment of disaster precaution and reduction effectively?

\section{Existing Problems}

\subsection{Information Deficiency Leads to Poor Contingency Plans}

West China is a hard-hit area of nature disasters with more than 80 percents sites of large collapse, landslide and debris flow. Meanwhile, West China suffers from drought or flood in some regions for years due to its role of climatic "transition zone", and snow mostly happens in the concentrated areas where ethnic nationalities live in, such as, Qinghai, Xinjiang, Inner Mongolia and Tibet, etc. 10 earthquakes of over 8.0 Richter magnitude scale occurred in mainland China, of which 7 happened in West China during 1990 to 2007. (Wu, 2008)From 1949 to 2007, the nature disasters like drought, flood, frozen disasters, snow disaster, earthquake, hail damage and wind damage in west China are more than 250 times, that is 6.3 times in average per year. (Rong, 2007).

Nature disasters happen with an increasing frequency in recent 5 years of China. Take the three particular years of severe disaster as example: in 2008, about 470 million people were afflicted by nature disasters, 88,928 were missing and dead, 26822 thousand of habitants were evacuated and relocated, with a direct financial loss of 1354,750 million Yuan (RMB). In 2010, the victims were 43 million or so, 7,844 people died in all those nature disasters and 18,584 thousand were emergency transferred and relocated, causing 5, 3399 million Yuan financial loss. And in 2012 the victims were 290 million or so, besides, the missing and dead tolls were 192 and 1,338, 11,096 thousand w were emergency transferred and relocated, causing a direct financial loss of 418,550 million Yuan. Those mentioned nature disasters were commonly occurred in west China provinces like Sichuan, Gansu, Hunan, Guizhou, Guangxi, Yunnan, Xinjiang, Tibet, etc. Among them, both the Wenchuan 8.0 magnitude earthquake in 2008 and the 2010 Yushu 7.1 magnitude earthquake resulted in tremendous economic losses and casualties, and severely affected the social development in West China.

When disasters occurred in West China in the past, information absence and communication discontinuity must be the main causes to insufficient response.

The disaster information delivering blockage is firstly reflected in the absence of hazards monitoring information. In fact, some of those hazards can be totally predicted and prevented with technological advancements. However, our sense of hazards is stayed in" experiential time" as we started late in monitoring disaster information and analyzing hazard data. Especially in west China, an area with complicated geographies and poor transportations, which make it difficult to layout monitoring equipments and monitoring disaster information and analyzing hazard data. What's more, it would be a hard decision to invest on those monitoring and information collection 
work. People seem to care more about buildings safety or evacuation drills compared with the collection of pre-warning information. Therefore, the information about nature disasters cannot be preinformed, not to mention taking effective precautions.

In another way, the disability of disaster information transmission also has a strong impact on the efficiency of emergency and treatment. Disaster is often featured by unexpected time, complicated environment, diversified information and uncertain need, etc. Modern communication system has poor resistance to disaster, so it cannot ensure the stable, reliable and efficient operation of emergency communication system. For instance, an unexpected snow attacked Junqu Village, Suojia Township, Yushu, Qinghai Province in 1993. As modern communication system completely broken down, villagers had to ride two horses by turns for 4 days and nights to local government for help. It also took the same time for the local government to report the situation to the county government. These disaster-stricken villagers were rescued after one week. In 2008, the earthquake-stricken areas in Wenchuan lost conventional communication system completely, so the outside world knew nothing about the areas within the early several hours after the earthquake of $8.0 \mathrm{Ms}$ occurred.

Thus, it is urgently needed to make use of the State's informationization development strategy for the western regions, systematically develop and reasonably utilize information resources, and constantly search for new and applicable technologies, in order to construct a structurally reasonable pre-warning, relief and reconstruction system.

\subsection{Fail to Communicate Is Prone to Lead Obstacles in Understanding}

Sudden onset social disasters in west China are the external and direct expressions of social contradictions, which are the result from culture difference and interest conflict. The accumulation of social contradictions, the interweave of disputes, the blockage of demands' information channels, the uncompleted and untimely information collection of grassroots government and the protection of handing processes from public viewing, all those above worsened conflicts and even lead to mass group incidents.

The "7.19" incident is taken as an example. Before the "7.19" incident happened in Dai, Lahu and Va Autonomous County, Menglian, Yunnan Province in 2008, seven group incidents had happened among peasants, rubber enterprise owners and governmental officials as the claims of stockade villages in Mengma Town and Gongxin Township for the interests in the plantation and trades of rubber had not be settled for a long time. As a matter of fact, the local people from Dai Nationality reported their hopes and claims to local government for many times, but never received any reply. Local government did not timely gather and understand the information and simply believed that these were only claims from gangsters, so they failed to timely and effectively deal with the reasonable claims of the people. Thus, the rubber planters from Dai Nationality accumulated grudges against rubber enterprises, which eventually transferred into the resentment toward local government. (Yin, 2008)

Besides the central topics on political probity and the people's livelihood, belief, religion and language, etc. are also the topics sensitive to the people of ethnic minorities in the cultural "combination areas" in West China. Thus, "network politics" and "E-government" is highly expected. To establish a public opinion information platform for timely pre-warning, handling and feedback of incidents has become an urgent demand of group incident emergency response management in governments at all levels. Nonetheless, what kind of information communication mechanism can boost the communication between government and public? And what kind of network information management system is beneficial to promote the common sense among different ethnic groups? Obviously, it is urgent to solve those problems.

\section{Discussion}

\subsection{Which One Is More Important, Database or GIS?}

All kinds of data relating to disasters must be relied on for disaster prediction, disaster evaluation and disaster relief, etc. West China is vulnerable to various geological disasters, the constriction of geological disasters database has being highly noticed. Since the 1990s, China's relevant departments and institutions have realized the importance of integrating and sharing the data of disasters and integrated numerous data of disasters. In 1995, China's natural calamities database was established to store and manage around 1.2 million pieces of data regarding various disasters from 2,364 county-level statistical units throughout the country, and collect the records of natural calamities before 1990 in China from different sources. (Wang, Shi, \& Zhu, 1995)

Nevertheless, it is urgent for China to improve the level of standardization and sharing with regard to its disaster database compared with similar projects in other countries. At present, there are only 5 serviceable disaster databases which are available for online search and with regular update (see Table 1). 
Table 1.

\begin{tabular}{|c|c|c|}
\hline Name & Maintained By & Website \\
\hline $\begin{array}{l}\text { China Meteorological Data } \\
\text { Sharing Service System }\end{array}$ & $\begin{array}{l}\text { National Meteorological } \\
\text { Information Center }\end{array}$ & http://cdc.cma.gov.cn/home.do \\
\hline & Plant Production & \\
\hline $\begin{array}{l}\text { Disaster } \\
\text { Database }\end{array}$ & $\begin{array}{l}\text { Management Department of } \\
\text { Ministry of Agriculture of } \\
\text { PRC }\end{array}$ & http://zzys.agri.gov.cn/zaiqing.aspx \\
\hline $\begin{array}{lll}\text { Marine } & \text { Disaster } & \text { Web } \\
\text { Database } & & \end{array}$ & $\begin{array}{l}\text { National Marine } \\
\text { Information Center }\end{array}$ & http://221.239.0.137/website/hyzh/viewer.htm \\
\hline $\begin{array}{l}\text { Thematic Database for } \\
\text { Human-earth System }\end{array}$ & $\begin{array}{l}\text { Institute of Geographic } \\
\text { Sciences and Natural } \\
\text { Resources Research, CAS }\end{array}$ & http://www.data.ac.cn/index.asp \\
\hline $\begin{array}{l}\text { Database for Geostress and } \\
\text { Geological Disasters in } \\
\text { China and Neighboring } \\
\text { Regions }\end{array}$ & $\begin{array}{l}\text { Institute of Geomechanics } \\
\text { of China }\end{array}$ & http://www.geomech.ac.cn/geo0503/ \\
\hline
\end{tabular}

Besides, those built databases failed to play a role in effective supervision. Most of the database's query and decision-making service mechanisms are imperfect; they also can't make efficient pre-warning towards nature disasters. Therefore, people move on to the application of GIS in recent years.

In the specific practice of disaster prevention and mitigation, the research and application of $3 \mathrm{~S}$ technology (remote sensing (RS), geography information systems (GIS) and global positioning systems (GPS)) has become a hot spot. For its feature of spatial information service, GIS is applied in disaster prevention and mitigation in higher width and depth. In the relevant academic research area, many scholars believe that the application of GIS in the disaster relief plan of West China is the prerequisite of disaster prevention and mitigation. (Lu \& Zhang, 2003)

As one of "ninth five-year" national science and technology projects, RS and GIS was introduced by researchers into the survey of environment and geology in the reservoir area of Xiluodu Hydropower Station at Jinsha River, and utilized to establish the geological disaster information system for landslides and mudslides within the reservoir area, and achieved good effect. (Gao \& Yang, 2003) During the construction of disaster pre-warning information system for the reservoir area of Three Gorges in China, researchers combine $3 \mathrm{~S}$ technology and ground monitoring network to monitor landslides and bank deformation based on the characteristics of geological disasters in the reservoir area of Three Gorges, and preliminarily establish the bank deformation and landslide monitoring and disaster pre-warning system for the reservoir area of Three Gorges. (Ouyang et al., 2005) For the numerous and frequent landslides in West China, GIS system is employed to dynamically simulate the whole process of landslide formation, growth \& evolution, disastrous occurrence, prevention and control, and reproduce the whole process of disaster, so as to further improve the quantitative research on the disaster of landslide. (He et al., 2004)

China has initiated the construction of national public incident pre-warning information release system project based on the information system of meteorological bureaus at all levels since November 2011, the research and production of GIS software is regarded as an crucial part. The project is intended to gather the information on four categories of incidents, namely, natural calamities, accidents, public health incidents and social security incidents by extensive use of GIS software productions, and also by use of various medias such as TV, broadcast, internet and phone messages, etc, ensure the delivery of pre-warning information to the public within 10 minutes and the coverage of pre-warning information for the public exceeds $82 \%$. (Yuan \& Lin, 2011)

It is foreseeable that GIS will play a very important role in the disaster emergency response system for West China. By combining RS and GPS technologies, GIS can comprehensively utilize landform analysis, valley analysis, land use research, spatial statistics analysis and mapping, etc. to monitor and predict the possible 
geological disasters in West China, so as to effectively improve the level of defense against natural calamities. With regard to emergency response and resources dispatching, GIS can indicate all kinds of data with different attributes on a map and accelerate the understanding and disposal of emergencies through the sharing, analysis and graphical presentation of data relating to disaster. Especially during emergency, GIS can help discover the best evacuation route for people, arrange the corresponding transportation and guarantee, and optimally allocate the resources for disaster relief and mitigation.

\subsection{Whether Social Networking Tools Helps or Not}

In the reflection on the "719" incident, Yunnan Province, where a lot of ethnic minorities live, has facilitated the "Yunan Practice of Online Political Consultation" to some extent. The governments at all levels have established online political consultation and many local officials have opened their microblogs. "The interactive mechanism of officials and netizens has gradually taken shape, through which netizens can participate in the political decisions and discussions online while officials can learn about the people's needs and opinions on political decisions online". (Yin \& Liu, 2011)

In December, 2009, a group incident happened in an wholesale market called Luosiwan in Kunming, Yunnan province, an official called $\mathrm{Wu}$ Hao registered the first provincial government micro blog "micro blog Yunnan". It had 2 million fans by the end of 2012 and 12 out of 16 cities opened their official micro blog by their information offices; two- thirds of counties opened their own micro blogs by propaganda departments. By the end of 2011, there were 504 micro blogs owned by Yunnan government agencies, which ranked $20^{\text {th }}$ in China, while officials ranked $14^{\text {th }}$ with 355 micro blogs. (National School of Administration, 2011)

After the "719" incident of Yunnan, which have been sprung up across web, the emergency response of the incident was regarded as "a completely possible pattern for dealing with emergencies" after the intervention of government. The incident was not considered to be caused by gangsters but recognized as a group incident of social security resulted from the economic conflicts between rubber peasants and enterprises. After the incident happened, the provincial government went to the villages of ethnic minorities and extensively collected information and public opinions, evaluated the policies and behaviors of governmental departments, and timely announced the corruptive practices and dereliction of duty involved in the incident by social network tools. In the "719" incident and those similar incidents happened afterwards, the collection and spread of online public opinion information, and the communication between officials, medias and netizens by the using of social network tools, made information disclosure as a turning point of the incident, and played a significant role in eliminating the contradictory. (Wang, 2008)

Along with the spread of broadband and digital TV, etc., internet has become an indispensible part of social structure in West China. Online public opinion has become an important force affecting social order. As shown in the research report released by Chinese Academy of Social Sciences in 2011, online public opinion played a positive role in helping governments solve $67 \%$ of serious public opinion incidents.

The use of social networking tools in pre-warning and relief in nature disasters is becoming increasingly obvious. The recent several years is taken as an example. Much information which is prone to lead sudden social incidents, especially those government scandals, was firstly exposed by internet, and then aroused the attention both from governments and mass media.

If there is no complete channel for information gathering, official information may be much different from actual situation. If there is no trust and coordination between ethnic minority villages and local governments, any emergency response plan will become useless. In network era, social networking tools has showed their force of constraint toward public power and also promoted publics` effectively participation in public affairs. It must be asked how to construct the public feelings supervision and investigation mechanism integrated with the unique natural and humanistic system of West China by using social networking tools, and unblock the information communication channel for the improvement of the people's livelihood; and how to perfect an information gathering institution with public credibility and open the network, in order to create a "harmonious but unique" internet environment and guarantee the practice effect of public opinion information in both system and mechanism. These questions must be taken into account in the construction of pre-warning information system for West China.

\subsection{The Vitality of Ethnic Groups' Traditional Information Channels}

In West China, there are 44 minority nationalities besides Han Nationality, who share some common things in their history, religion, architecture, music and literature, etc. at the places where they live together, but have some large differences in time and space. 
In the process of historical evolution, ethnic minorities have cultivated their unique wisdoms of survival and established their unique information channels based on psychological field of ethnic culture, by virtue of special living environments, unique natural resources, prominent ethnic cultures and deep-rooted religions. Hence, it is of great significance to appropriately reserve and utilize the unique information tools of ethnic minorities and apply them in the relief of disasters when mainstream media become useless and information channel is blocked.

First of all, it is significant to figure out if ethnic groups' traditional methods of communication and emergency still get its value and can we have a proper reservation towards that and apply them to the relief of sudden-unset disasters where mainstream medias get a "aphasia" and information dissemination blockage? In the modern society, communication systems are often destructed thoroughly during extremely destructive natural calamities. Nothing can be arranged if information is not available. For instance, ethnic minorities in West China are good at delivering various kinds of information by using various instruments and their unique tunes and frequencies. The Dong minorities` long drum is taken as an example. Usually, slow, deliberate drumbeats means the village elders are call for a meeting in drum-tower. And when it comes to rapid drumbeats, it means something emergency like fire disaster happened and villagers should gather together, in order to face disasters together. Once upon a time, carrier pigeons and horse caravans were main methods of information dissemination in west China villages; it must be an effective way in copy with emergency if carrier pigeon lovers both in urban areas and villages create a communication net.

Secondly, once those nature disasters in west China happened, natural calamities often block or break highways, which are very difficult to repair and rebuild. If there is no rural road and good weather, it is very difficult to airdrop supplies. Thus, can traditional means of transport be taken as a supplementary way during emergency based on the geographical and cultural features of ethnic areas? For instance, the cultural zone of Chuan, Dian and Tibet in Hengduan Mountains and plateaus with high altitude reserves the simple means of transportation created by ethnic minorities, such as, some tools for crossing rivers, including "overhead chain" of Lisu Nationality, Dulong Nationality and Luoba Nationality and "manger boat" of Nu Nationality. Similarly, "horse caravans", an effective and cheap traditional mean of transport, should not be overlooked in the development of modern traffic in the southwestern regions.

\section{Suggestions}

Information-sharing-based linkage mechanism means that government, community, school and family work together and coordinate the disposal of a disaster through good communication and resource integration. Government is the leader, so it timely releases all kinds of information on the disaster to the outside and makes reasonable decisions. Community, school and family are the soldiers, who can improve their own capabilities of self-rescue in the disaster and also help each other after learning about the disaster and acquiring the skills of disaster prevention by the construction of a "precaution and alleviation" knowledge network. Through establishing a linkage mechanism, government can made reasonable decisions based on the humanistic and natural characteristics of west ethnic areas, while community, school and family can also learn about relevant policies and information timely. In this way, collaboration can enhance the overall capability of disaster response in the whole society.

\subsection{Respect for the Traditions of Ethnic Groups}

Information dissemination and knowledge reserve should take more ethnic culture features into account. Information is disseminated once people can figure out information symbols and are willing to accept those symbols. People acquire knowledge of disaster conservation and alleviation from religious sites and ceremonies due to the poor information condition in west ethnic minority villages. Thus, it is still an effective way to enhance people's reactivity in face of disasters by the rational utilization of religions, festivals, models and public opinions, etc, into the teaching of disaster generating principles and countermeasures. The unique information channel based on ethnic culture is formed during the long time living and production, manners and customs and daily rituals. This channel is easily accepted and can both correctly delivering information and have a lasting impact. Therefore, it's crucial to keep the information channel open when disasters happen. The key work of disaster prevention and reduction is accurately gathering and timely delivering disaster information.

To pay attention to traditional information tools is to explore and use those outstanding traditional cultures and wisdoms of various races in the disaster prevention and control of West China. For instance, there are rock paintings in Cangyuan of Yunnan Province and Zuojiang of Guangxi Province. Ancestors used stone tools to record their scenes of production and life and their measures against wars and natural calamities, etc., and the Baiheliang hydrological engravings in Filing, Chongqing keep the historical information on flood prevention and control, which can be used by posterities against floods. 
Meanwhile, West China demonstrates the characteristics of cultural "combination" due to its unique natural and geographical conditions and diversified ethnic cultures. As a basis for ethnic borders, ethnic culture leads to the integration and co-existence of diversified cultures as well as the cultural conflicts during the socialization of races. From this approach, the construction of disaster relief system must focus on effectively managing disaster information and making reasonable decisions based on the unique duality of natural and humanistic systems in West China, the respect for ethnic cultures and the reasonable utilization of traditional science and technology.

\subsection{Use Amateur Communication Systems Effectively}

Decisions on disaster relief depend significantly on the accurate, timely and quick transmission of information. Nevertheless, if conventional communication system is thoroughly destroyed by severely destructive natural calamities, communication resources should be reasonably integrated to construct a comprehensive emergency communication system based on the combination of amateur and professional, in order to acquire the information on the disaster timely and determine the correct emergency measures.

To ensure the efficient operation of emergency command system and disaster response work, it is especially important to establish a professional emergency communication system. In the National "Twelfth Five-year" Plan for Comprehensive Disaster Prevention and Mitigation released by Ministry of Civil Affairs of PRC, the agenda includes constructing a disaster prevention and mitigation informationization network platform, enhancing the integration, interconnection and intelligent processing of comprehensive disaster prevention and mitigation information and strengthening the information sharing of disaster prevention and mitigation. With regard to monitoring and communication means, it also puts forward improving the construction of environmental and disaster monitoring \& forecasting satellite and airborne remote sensing system, making full use of various satellite remote sensing resources at home and abroad, exchanging all kinds of information on field disaster relief, and enhancing the information service level of disaster prevention and mitigation.

Amateur communication system is highly flexible and capable to defend against disasters, so it can be used as a powerful supplement to conventional communication system. During Wenchuan earthquake in 2008, efficient communication means were urgently needed for numerous earthquake-stricken areas, so a lot of amateur radio fans were applied to participate in the disaster relief program. Within five days, China Radio Amateur Club established an emergency communication network and put it into operation to play a prominent role in supporting government's emergency communications and guaranteeing the transportation of materials and relocation of injured people. Therefore, the vital amateur communication system can be an important information channel when conventional communication system breaks down.

What is more important, attention should be paid to perfect the connection between amateur communication system and professional communication system, in order to ensure the efficient operation of emergency command system. In some areas of West China, communication means of different departments cannot be interconnected due to the division of administrative governance and interests, which may easily reduce the accuracy of emergency communication among police, firefighting, first aid and other departments in the process of disaster relief. As a result, it is necessary to strengthen the organic combination of amateur and professional communication systems, with an aim to realize their effective connection during emergency.

\subsection{Enhance the Targeted Research in Sudden-Onset Disasters}

Government must lead the interdisciplinary and cooperative study. Government finds it more difficult to manage decisions and provide services due to numerous religions, languages, folk customs and vulnerable ecological environments, so it must make scientific decisions based on the local data of economy, society, customs, geology and environment, etc. Thus, the interdisciplinary and cooperative study on natural and social disasters will be indispensable. The expert consultation team based on ethnology, ecological anthropology, sociology, and other social sciences should be established with the assistance of existing universities and research institutes, in order to perform the social and cultural argumentation, evaluation and planning of project development and conduct the comprehensive and insightful study on the prevision of possible social disasters.

Governments at all levels should consider the opinions from expert consultation team about developing resources, handling group incident and making relevant decisions. In the hydropower, minerals, forestry, and other industries, enterprises and institutions hire a certain quantity of professionals with the knowledge of anthropology, sociology, ethnology and economics in order to guarantee that resources development, economic construction and cultural development match with the objective reality of ethnic areas in West China, satisfy the wills and requirements of various races, and avoid the contradictions, disputes and conflicts among races. 


\subsection{Pay Attention to the Transparency of Disaster Information}

Information disclosure is often an important way for government to take initiative and win trust during the emergency of group incident. After a disaster happens, government should timely gather the information from various parties. With very limited time, resources and information, etc., it appears very crucial to release the latest information on the disaster. On one hand, this can win the time for government to deal with the disaster. On the other hand, it can help all walks of life learn about the authoritative information to participate in the disaster relief program, so as to eliminate the rumors from other channels and calm down the public in the stricken areas.

In the past, the function of coping with disasters was burdened by different governmental departments in China. However, these departments often lacked the communication of information and their information channels were not compatible, so their division of work and collaboration were often affected. When dealing with a disaster, local government had to report level by level to the government of higher level, which affected the timeliness of decision, delayed the rapid handling of the disaster, and even caused other disasters. Therefore, it is very important to establish a communication platform with unified standards and information sharing under the leadership of government, so that relevant departments of governments at all levels can, while dealing with any natural calamities, collect the information from all parties timely, coordinate various aspects, rapidly make reasonable decisions, and accurately release information.

\subsection{Establish an Anti-disasters Knowledge Network among Communities, Schools and Families}

After Wenchuan earthquake in 2008, the Chinese Government determined that May 12 would be Disaster Prevention and Mitigation Day every year, strengthened the construction of infrastructures for disaster prevention and mitigation, periodically organized the drills of escape and refuge, and established the collaborative mechanism of disaster response for community, school and family. Moreover, China also established the administrative management system of earthquake prevention and disaster mitigation, developed a disaster prevention education base on the ruins after earthquake, published the readings for disaster response, and required primary and middle schools to open the compulsory courses of disaster prevention. Families stored the goods for disaster relief voluntarily.

When it comes to the topic of "establishing disaster precaution knowledge network" during our research activity, the respondents reached an agreement and they think several situations should be noticed while establishing that knowledge network. (1) As they speak different languages, the people from ethnic minorities cannot use the disaster prevention training readings written in mandarin Chinese, so they have little knowledge of natural calamities and their prevention. (2) Cultural conflicts are combined with language barrier, religious feelings and economic interests, etc., so the people from ethnic minorities are vulnerable to unexpected events. Especially, if group incident happens in the disguise of race or religion, it may quickly spread and expand. (3) With regard to natural calamities, most of ethnic villages locate in the areas where geological disasters often occur, and lack the shelters. Moreover, most of young people go to work in other places and only old people and children are left in villages, so they lack the capability of self-rescue.

Therefore, as the soldiers for comprehensive prevention and control in the society, it is crucial for community, school, family and other social institutions and people effectively improve their capabilities of self-rescue and mutual help by learning the knowledge of disaster and mastering the skills of disaster prevention through that anti-disaster knowledge network. In the process, their awareness of disaster prevention and knowledge network are crucial. In most of villages in West China, there is "Peasant Library", rural cultural station and other institutions. However, it is still necessary to study how to effectively give play to the roles of "Peasant Library", rural cultural station, rural primary and middle schools in the education system of disaster prevention and mitigation.

To compile the readings and textbooks for disaster prevention based on the characteristics of traditional ethnic minority cultures is also a very helpful method. The awareness of disaster prevention should not be only demonstrated in the school education, but also covered in the education systems for all people. In West China, ethnic minorities have their own features with regard to location, oral language and writing language, etc. For the people of different ages, it is necessary to compile the readings and textbooks suitable for their cognition. In this way, these readings and textbooks can be accepted by the people in terms of form and content, in order to enhance their awareness of disaster prevention, learn the knowledge of disaster prevention, master the skills of disaster prevention and truly realize the effect of disaster prevention and mitigation education.

\section{Conclusion}

Frequent natural and social disasters have become one of the reasons for backward economic development and 
nevertheless, informationization framework must avoid or reduce the hazards caused by disasters to the maximum, and must be suitable for traditional ethnic nationality cultures. Moreover, it should consider the nature and ecology in the western regions, combine traditional emergency response practices with modern relief methods, facilitate the understanding and social instability in West China, so it is very urgent to construct an informationization "comprehensive relief" system suitable for the disasters in West China by bring social forces together.

Nevertheless, informationization framework must avoid or reduce the hazards caused by disasters to the maximum, and must be suitable for traditional ethnic nationality cultures. Moreover, it should consider the nature and ecology in the western regions, combine traditional emergency response practices with modern relief methods, facilitate the understanding and communication of various ethnic cultures, advocate the "disaster prevention education" in communities and on campuses, and strengthen the interdisciplinary and cooperative study of social sciences, in order to effectively prevent, cope and deal with all kinds of natural and social disasters.

\section{References}

Gao, G. P., \& Yang, J. H. (2006). Application of GIS in the study of geologic hazards. Yangtze River, (6), 32-33.

He et al. (2004). Development about prevention and cure information and decision support system of the geological hazard on ARCGIS. Journal of Jilin University (Earth Science Edition), (4), 601-606.

Lu, J. F., \& Zhang, F. P. (2003). GIS and protecting against and mitigating disaster. South China Journal of Seismology, (2), 64-67.

National school of Administration. (2011, November 12). An assessment report of Chinese government affair micro-blogs in 2011. Retrieved February 8, 2012, from http://news.xinhuanet.com/politics/2011-11/22/c_111187217.htm

Ouyang et al. (2005). Landslide monitoring system of typical Three Gorges Reservoir region based on 3S technology and ground deformation observation. Chinese Journal of Rock Mechanics and Engineering, (18), 203-210.

Rong, N. (2007). Preliminary study on the natural calamity in the west nationalities area in the 40 years since the founding of the PRC. Nationalities Rsearch in Qinghai, 4(2), 144-145.

Shi, L. (2006). An analysis of early warning system of emergencies in ethnic regions. Journal of Xin Jiang University, (4).

Wang et al. (1995). Establishment and application of natural disaster database of China. Journal of Beijing Normal University (Natural Science), (3), 121-126.

Wang, Y. (2008, September 9). “719 Incident” in Menglian: An Example for Handling Unexpected Events. Retrieved October 16, 2012 from http://hunan.voc.com.cn/article/200809/200809091040261229.html

Wu, M. (2008). Top 10 earthquakes happened in China in 2oth century. Xiang Yin, (7), 45-47.

Yin, H. (2008, September 17). The latest report of “719 incident” in Menglian. Retrieved October 16, 2012 , from http://zqb.cyol.com/content/2008-09/17/content_2359961.htm

Yin, Y. G., \& Liu, R. S. (2011). Localization and socialization of new media in China. In Y. G. Yin (Ed.), China New Media Development Report 2011 (pp. 1-12). Beijing: Social Sciences Academic Press.

Yuan, M. C., \& Lin, H. (2011, November 12). China Initiates the Constructions of National Emergent Public Event Pre-warning Information Release System. Retrieved October 16, 2012, from http://news.xinhuanet.com/politics/2011-11/22/c_111187217.htm

\section{Copyrights}

Copyright for this article is retained by the author(s), with first publication rights granted to the journal.

This is an open-access article distributed under the terms and conditions of the Creative Commons Attribution license (http://creativecommons.org/licenses/by/3.0/). 